5

6

8

9

\title{
Nanostructured large-pore zeolite: the enhanced accessibility of active sites and its effect on the catalytic performance
}

\author{
Aqeel Al-Ani ${ }^{a, b *}$; Cátia Freitas ${ }^{a}$; Vladimir Zholobenko $^{a *}$
}

a School of Chemical and Physical Sciences, Keele University, Keele, ST5 5BG, United Kingdom

${ }^{b}$ Oil Marketing Company (SOMO), Baghdad, Iraq

\begin{abstract}
Zeolites Y, ZSM-5, beta, mordenite and LTL were converted into hierarchical meso-microporous catalysts applying the surfactant templating strategy and the resulting materials were utilised as catalysts for esterification and aldol condensation reactions for the production of the second generation biofuels and platform chemicals from biomass derived molecules. The relationship between the catalytic performance and the accessibility of active sites in zeolites was examined using FTIR spectroscopy of adsorbed pyridine, 2,4,6-trimethylpyridine and 1,3,5triisopropylbenzene. It was found that the esterification of oleic acid can be enhanced by the presence of strong acid sites in zeolites and their improved accessibility. In the aldol condensation reaction, furfural conversion over hierarchical catalysts also increased as compared to the parent zeolites. However, K-forms of the studied zeolites exhibited a higher conversion and selectivity toward the desired reaction products in comparison with their H-forms. Overall, mesostructured zeolites demonstrated an improved catalytic performance as a result of increasing accessibility of the zeolite active sites.
\end{abstract}

Keywords: hierarchical zeolites; in situ FTIR; acid site accessibility; esterification; aldol condensation.

* Corresponding authors:

A. Al-Ani, e-mail address: a.a.t.al-ani@keele.ac.uk

V. Zholobenko, e-mail address: v.l.zholobenko@keele.ac.uk 


\section{Introduction}

In the recent years, significant attention has been focused on sustainable green energy applications due to the oils price fluctuations, environmental issues and the cost of high-quality fuels. To date, the main feedstocks utilised as renewable bio-refinery sources are triglycerides (TG) and lignocellulose [1-3]. Aldol condensation reaction between furfural and ketones can be considered as a potential route for the production of valuable compounds with longer carbon chains from short-chain biomass-derived molecules using either basic or acidic catalysts [4-7]. Another important process for the bio-refinery applications, the esterification reaction between the free fatty acids (FFA), which are present in a mixture with TG in the bio-oil feedstocks, and small linear alcohol molecules in the presence of an acid catalyst producing fatty acid methyl esters (FAME). This reaction is essential for feedstocks containing high amounts of FFA, which can inhibit the activity of the basic catalyst that is employed to convert TG into biodiesel via transesterification reaction $[1,8,9]$. Considerable research has been undertaken utilising recoverable and non-corrosive materials such as zeolites, metal oxides, metal-organic frameworks, and metal-substituted zeotypes in these reactions [10-15]. However, many catalysts show poor performance because of the mass transport limitations in microporous solids as well as weak acidity and low hydrothermal stability of mesoporous MCM-41 and SBA-15 type materials [16-18]. To counter these problems, a number of methodologies for the preparation of macro-meso-microporous materials have been developed, some of which have been successfully employed in biomass processing and bio-oil upgrading [1927].

For catalytic applications involving renewable feedstocks, it is important to maximise the accessibility of acid sites within the porous networks of zeolites [28-30]. Acid sites located on the external surface of a zeolite are commonly accessible; the accessibility within the microporous system is dependent upon the dimensions of the pores relative to the guest molecule [31,32]. Adsorption of various FTIR probe molecules monitored by FTIR represents an important tool for evaluating the location of acid sites in different zeolitic structures. For instance, adsorption of alkylpyridines has been used for the analysis of acid site distribution in MOR and MFI zeolites prepared with different degrees of intracrystalline mesoporosity [33,34]. Such bulky probe molecules have limited access to some micropores due to their large kinetic diameter, and therefore, can be used to quantify the accessibility of BAS in hierarchical zeolites [35].

In our recent work, the surfactant-templating mesostructuring approach has been utilised for the preparation of a number of large-pore zeolites, including BEA, FAU, MOR and LTL. The catalyst preparation involves a post-synthesis modification using long-chain alkyl quaternary amine cationic surfactant in basic media, which results in the formation of a network of ordered mesopores within the zeolite [36]. The present work is focused on the FTIR characterisation of these nanostructured 
catalysts and on the effect of their properties and accessibility of the active sites on the catalytic performance in esterification of oleic acid and aldol condensation of furfural with acetone as potential bio-refinery related applications.

\section{Experimental}

\subsection{Synthesis of hierarchical zeolites}

$\mathrm{NaY}$ zeolite (CBV100, Si/Al=2.6, Zeolyst) was modified following the previously described procedure [36]. The calcined meso-microporous zeolite was ion-exchanged using either (i) $0.5 \mathrm{~mol}$ $\mathrm{L}^{-1}$ of $\mathrm{NH}_{4} \mathrm{NO}_{3}$ solution (Sigma-Aldrich, $99 \%$ ) at $80^{\circ} \mathrm{C}$, or (ii) $0.1 \mathrm{~mol} \mathrm{~L}^{-1}$ solution of $\mathrm{KNO}_{3}$ (SigmaAldrich, $99 \%$ ) at $80^{\circ} \mathrm{C}$. The resulting solids were separated and washed with deionised water to obtain (i) $\mathrm{MNH}_{4}-\mathrm{Y}$ and (ii) MK-Y zeolites. Potassium exchanged zeolite $\mathrm{Y}$ (denoted as $\mathrm{KNa}-\mathrm{Y}$ ) with $\mathrm{Si} / \mathrm{Al}=2.6$ was provided by Riogen.

$\mathrm{NH}_{4} \mathrm{MOR}$ (Zeolyst, CBV 21A, Si/Al=10) and $\mathrm{NH}_{4} \mathrm{BEA}$ zeolites (Zeolyst, CP814C Si/Al=19) were converted into hierarchical zeolites (MMOR) and (MBEA) according to the patent reported by Ying and Garcia-Martinez [37] (see Ref. 36 for further details). The calcined products were labelled as MMOR and MBEA.

$\mathrm{NH}_{4}$-forms of ZSM-5-15 and ZSM-5-40 zeolites (Zeolyst, CBV 3024E Si/Al=15 and CBV $8014 \mathrm{Si} / \mathrm{Al}=40)$ were treated according to the desilication method described in $[36,38]$. The obtained samples were ion-exchanged using $0.5 \mathrm{~mol} \mathrm{~L}^{-1} \mathrm{NH}_{4} \mathrm{NO}_{3}$ solution at $80^{\circ} \mathrm{C}$, washed with deionised water, dried and calcined; the samples were labelled as MZSM-5-15 and MZSM-5-40.

NaK-LTL zeolite (Tosoh, HSZ-500KOA, Si/Al=3.2) was treated as described in [36]. The calcined mesostructured zeolite was ion-exchanged with either (i) $0.5 \mathrm{~mol} \mathrm{~L}^{-1}$ of $\mathrm{NH}_{4} \mathrm{NO}_{3}$ at $40^{\circ} \mathrm{C}$ for $1 \mathrm{~h}$, or (ii) $0.1 \mathrm{~mol} \mathrm{~L}^{-1}$ solution of $\mathrm{KNO}_{3}$ at $40^{\circ} \mathrm{C}$ for $1 \mathrm{~h}$. The final samples (i) $\mathrm{MNH}_{4}-\mathrm{L}$ and (ii) MK-L were filtered, washed with deionized water and dried overnight.

\subsection{Characterisation of zeolites catalysts}

A comprehensive structural characterisation of all the materials utilised in this work was carried out using powder X-ray diffraction (XRD), scanning and transmission electron microscopy (SEM and TEM), low temperature nitrogen adsorption, solid-state NMR and FTIR spectroscopy. A detailed description is available in Ref [36].

To gain a better understanding of the acidic properties of hierarchical zeolites, infrared spectroscopy of adsorbed guest molecules was utilised to evaluate the accessibility of their acid sites. Prior to FTIR studies, the zeolites were pressed into self-supporting discs $(\sim 10 \mathrm{mg})$ and pretreated in situ in an IR cell at $450^{\circ} \mathrm{C}$ under vacuum $\left(1^{\circ} \mathrm{C} / \mathrm{min}\right.$ temperature ramp; $\left.10^{-5} \mathrm{Torr}\right)$ for 5 h. The adsorption experiments with different probe molecules were monitored using a Thermo iS10 
101

102

103

104

105

106

107

108

109

110

111

112

113

114

115

116

117

118

119

120

121

122

123

124

125

126

127

128

129

130

131

132

133

134

135

spectrometer equipped with a DTGS detector at a spectral resolution of $4 \mathrm{~cm}^{-1}$. An excess of probe molecules was introduced into the IR cell and the physisorbed species were removed by evacuation at the adsorption temperature. Adsorption of 1,3,5-triisopropylbenzene (TIPB, $\mathrm{C}_{15} \mathrm{H}_{24}$, Acros Organics, 95\%) was performed at room temperature. Pyridine $\left(\mathrm{C}_{5} \mathrm{H}_{5} \mathrm{~N}\right.$, Acros Organics, 99.5\%), 2,6-di-tert-butyl-pyridine $\left(\mathrm{C}_{13} \mathrm{H}_{21} \mathrm{~N}\right.$, Sigma-Aldrich, 97\%), 2,6-dimethylpyridine $\left(\mathrm{C}_{7} \mathrm{H}_{9} \mathrm{~N}\right.$, SigmaAldrich, 99\%) and 2,4,6-trimethylpyridine (collidine, Coll, $\mathrm{C}_{8} \mathrm{H}_{11} \mathrm{~N}, \mathrm{BDH}$ reagents, 95\%) were adsorbed at $150-250{ }^{\circ} \mathrm{C}$. The obtained infrared spectra were analysed (including integration, subtraction, and determination of peak positions) using specialised Thermo software, Omnic.

For the quantification of the zeolite acidic properties using FTIR spectra of adsorbed pyridine, the following values of the molar absorption coefficients were applied: ЧัBAS, MFI)=1.08, ЧัBAS,

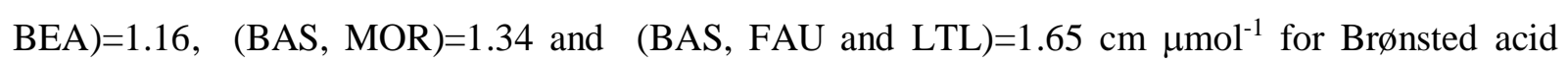

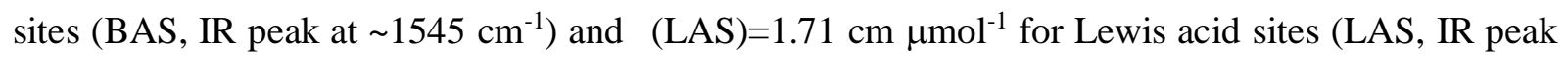
at $\sim 1455 \mathrm{~cm}^{-1}$ ). These values were determined using the AGIR set-up [35] on self-supported discs, which were activated in the IR in situ cell at $450^{\circ} \mathrm{C}$ under a flow of $\mathrm{Ar}$ for $5 \mathrm{~h}\left(\mathrm{ramp} 1{ }^{\circ} \mathrm{C} / \mathrm{min}\right)$. FTIR spectra of the samples were collected using a Thermo Nicolet 6700 spectrometer equipped with an MCT detector (spectral resolution of $4 \mathrm{~cm}^{-1}$ ) and the mass changes of the same sample were monitored by a SETSYS-B Setaram microbalance (accuracy of the mass measurements was better than $\pm 1 \mu \mathrm{g}$ ). The accessibility of BAS was calculated as the percentage of the intensity changes in the difference FTIR spectra of the bridging OH-groups before and after adsorption of the probe molecules. In addition, for calculating the concentration of BAS accessible to collidine (on the external surface and in mesopores of the studied zeolites), the literature value of ÜBAS-Coll $)=10.1$ $\mathrm{cm} \mu \mathrm{mol}^{-1}$ was used [39]. The error margin for the acid site quantification was estimated as $\pm 5 \%$.

\subsection{Reaction Studies}

Esterification offatty acids. The esterification of FFA with methanol in the presence of various zeolites was carried out in a Biotage Initiator+ microwave synthesiser (Biotage). Specially designed 10 -and 20 -ml glass vials were used as batch reactors operating at $100-250^{\circ} \mathrm{C}$ and $1-20$ bar. The experiments were also repeated in the Monowave-50 reaction system (Anton Paar). In a typical reaction run, the feedstock comprising $1 \mathrm{~mL}$ of oleic acid (Sigma-Aldrich, 99\%) and $10 \mathrm{~mL}$ of grapeseed oil was reacted with excess methanol (Fisher Scientific, 99.99\%) at 1:4 molar ratio (oleic acid to methanol) at $100^{\circ} \mathrm{C}$ for 5-60 min, in the presence of $0.45 \mathrm{~g}(\sim 5 \mathrm{wt} \%$ of the feedstock oil) of a freshly calcined catalyst $\left(5 \mathrm{~h}\right.$ at $450^{\circ} \mathrm{C}, 1^{\circ} \mathrm{C} / \mathrm{min}$ ramp) with continuous stirring. The percent FFA was determined according to the method reported in ref [40] before and after the addition of oleic acid. Fatty acid composition of the oil was obtained by gas chromatography-mass spectrometry. The analysis conditions for this method and the oil properties are summarised in Tables S1 and S2. 
Aldol condensation. The Biotage microwave reactor was employed for the reaction between the furfural (Sigma-Aldrich, 99\%) and acetone (Fisher Scientific, 99.99\%) over the zeolite catalysts using sealed $10 \mathrm{~mL}$ glass vials as a batch reactor. In a typical catalytic run, $0.2 \mathrm{~g}$ of calcined zeolite catalyst ( $5 \mathrm{~h}$ at $450^{\circ} \mathrm{C}, 1^{\circ} \mathrm{C} / \mathrm{min}$ ramp) was mixed with $5 \mathrm{~mL}$ of the acetone - furfural mixture with a molar ratio of $10: 1$ and reacted for $20-180$ min under stirring at $160^{\circ} \mathrm{C}$. After the reaction, $0.1 \mathrm{~mL}$ of the isolated liquid product was mixed with $10 \mathrm{~mL}$ of the internal standard solution $(0.2 \mathrm{v} \%$ of nonane in MTBE). The analysis of the reaction products was performed on an Agilent GC 7890A equipped with a mass detection system $5975 \mathrm{C}$ and a HP-5 $(30 \mathrm{~m} \times 250 \mu \mathrm{m} \times 0.25 \mu \mathrm{m})$ capillary column (see Table S1b and Figure S1). The conversion and selectivity error estimated from the repeated reaction tests was $\pm 5 \%$. Catalytic performance of zeolites was described in terms of furfural conversion, the selectivity and yield of 4-(2-furyl)-3-buten-2-one (FAc) or 4-methylpent-3-en-2-one (4-MP) according to [41].

Catalyst reusability. Consecutive tests were performed by separating the catalysts, rinsed with methanol and acetone and dried overnight at $40^{\circ} \mathrm{C}$. Then, the recycled catalysts were calcined under the same conditions as prior to the initial reaction and utilised again. The same reaction conditions were used in four recycle runs for these catalysts.

\section{Results and discussion}

The TEM analysis of the studied hierarchical zeolites and their textural properties, which are summarised in Table S3, indicate that well-defined networks of interconnected micro- and mesopores are formed in these materials following their surfactant-templating treatment [36]. The intracrystalline nature of uniform mesopores and a degree of long-range ordering have been previously confirmed for the large-pore (12-MR) FAU, LTL and MOR zeolites. In zeolite BEA (12MR), the formation of mesopores is complicated by the random intergrowth of polymorphs $\mathrm{A}$ and B, whereas the medium-pore ZSM-5 zeolite is relatively ñresistantò to this treatment as the 10-MR micropores are by and large inaccessible to the surfactant species. Hence, the mesopores produced in BEA and ZSM-5 have a broader pore size distribution and show little evidence of the long-range order [36].

\subsection{Accessibility of acid sites in hierarchical zeolites}

FTIR studies using adsorption of probe molecules is an important means for comprehensive characterisation of acid sites in zeolite based catalysts, including their nature, strength and accessibility [35,42]. Pyridine has been used in this study in order to determine the number of BAS and LAS from the intensities of $\mathrm{Py}-\mathrm{H}^{+}$peak at $\sim 1545 \mathrm{~cm}^{-1}$ and Py-L peak at $\sim 1455 \mathrm{~cm}^{-1}$ (Figure S2). The surfactant templating mesostructuring treatment leads to a decrease in the concentration of 
BAS and an increase in the concentration of LAS for all zeolitic structures (Figure 1). In agreement with previous studies, these changes result from partial desilication and dealumination of the modified zeolites followed by their calcination [28]. FTIR spectra of the modified samples also show a decrease in the intensity of the bridging OH-groups and a concurrent increase in the intensity of the peak at $3745 \mathrm{~cm}^{-1}$ assigned to the external Si-OH groups, confirming the removal of the framework $\mathrm{Al}$ and $\mathrm{Si}$ atoms during the formation of mesopores (Figure S3).

The accessibility of acid sites in both parent and mesostructured zeolites has been monitored by FTIR spectroscopy of adsorbed Py, Coll and TIPB, and the results are summarised in Table 1. The relatively large size of Coll molecules $(7.4 \AA)$ prevents their access to BAS in the micropores of ZSM-5 allowing the determination of the BAS accessibility of hierarchical ZSM-5 zeolites. Both parent and hierarchical ZSM-5 contain a small and similar number of BAS accessible to the bulky Coll molecules (Figure S4); these acid sites are located on the external surface or close to the pore mouths of the parent zeolite. The desilication of ZSM-5 in the presence of CTAB surfactant, which is probably excluded from the $10-\mathrm{MR}$, leads to the formation of secondary mesopores with a rather modest increase in the accessibility of BAS to Coll.

The size of Coll molecule is very similar to the pore dimensions of the 12-MR channels along [100] (7.7 $\AA$ × 6.6 $\AA$ ), but is somewhat larger than the 12-MR channels along [001] (5.6 $\mathrm{\AA} \times 5.6 \AA)$ in the BEA structure. However, according to the FTIR data, this probe can access all bridging OHgroups in both the parent and mesostructured zeolites BEA (Table 1). For MOR and MMOR, although Coll adsorption has been used to determine the accessibility of BAS in meso-microporous mordenites [43], our data demonstrate that the diffusion of this test-molecule into the micropores is dependent on the temperature and duration of the experiment. Therefore, additional experiments utilising a different probe molecule, TIPB, have been carried out to evaluate the changes in accessibility of BAS in these large-pore zeolites following the mesostructuring treatments. Adsorption of TIPB (kinetic diameter of $\sim 8.5 \AA$ ) at $30^{\circ} \mathrm{C}$ on ZSM-5, MOR and BEA zeolites leads to a significant reduction in the intensity of the $\mathrm{Si}-\mathrm{OH}$ band at $3745 \mathrm{~cm}^{-1}$. The changes in the intensity of the Si-OH-Al band at $\sim 3610 \mathrm{~cm}^{-1}$ are best interpreted from the difference spectra (Figures 2, S5 and S6). Indeed, a low intensity negative peak at $\sim 3610 \mathrm{~cm}^{-1}$ is observed for both parent and mesoporous zeolites; this corresponds to the ñexternalò acidic Si-OH-Al groups interacting with the hydrocarbon molecules by forming a hydrogen bond. Hence, the intensity of this peak can be used to quantify the accessibility of bridging $\mathrm{OH}$-groups, which increases from 10 to $22 \%$ for BEA and from 2 to $12 \%$ for MOR following the mesostructuring treatment since there are more acid sites interacting with TIPB in the mesopores or in the pore mouths of the zeolite micropores in comparison with the parent structures. 


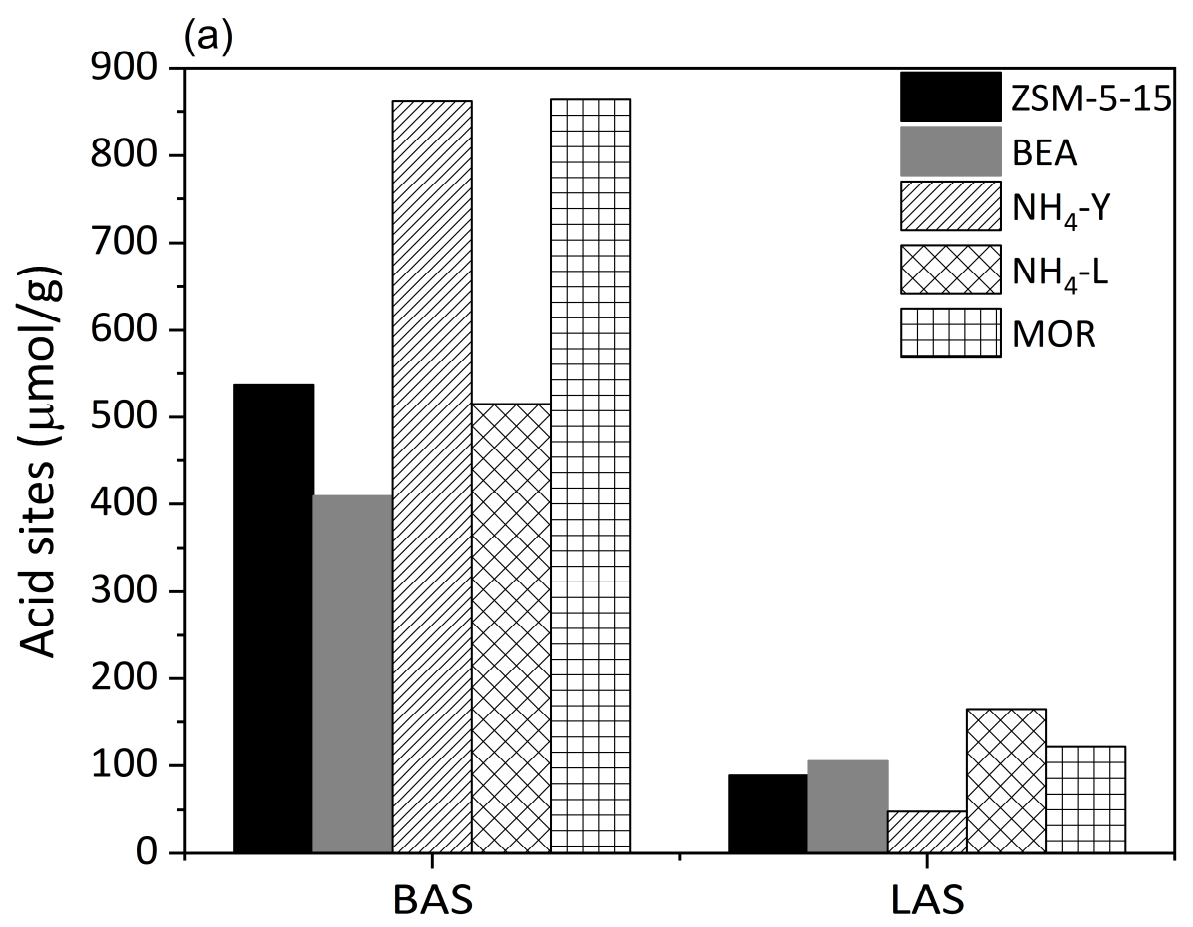

205

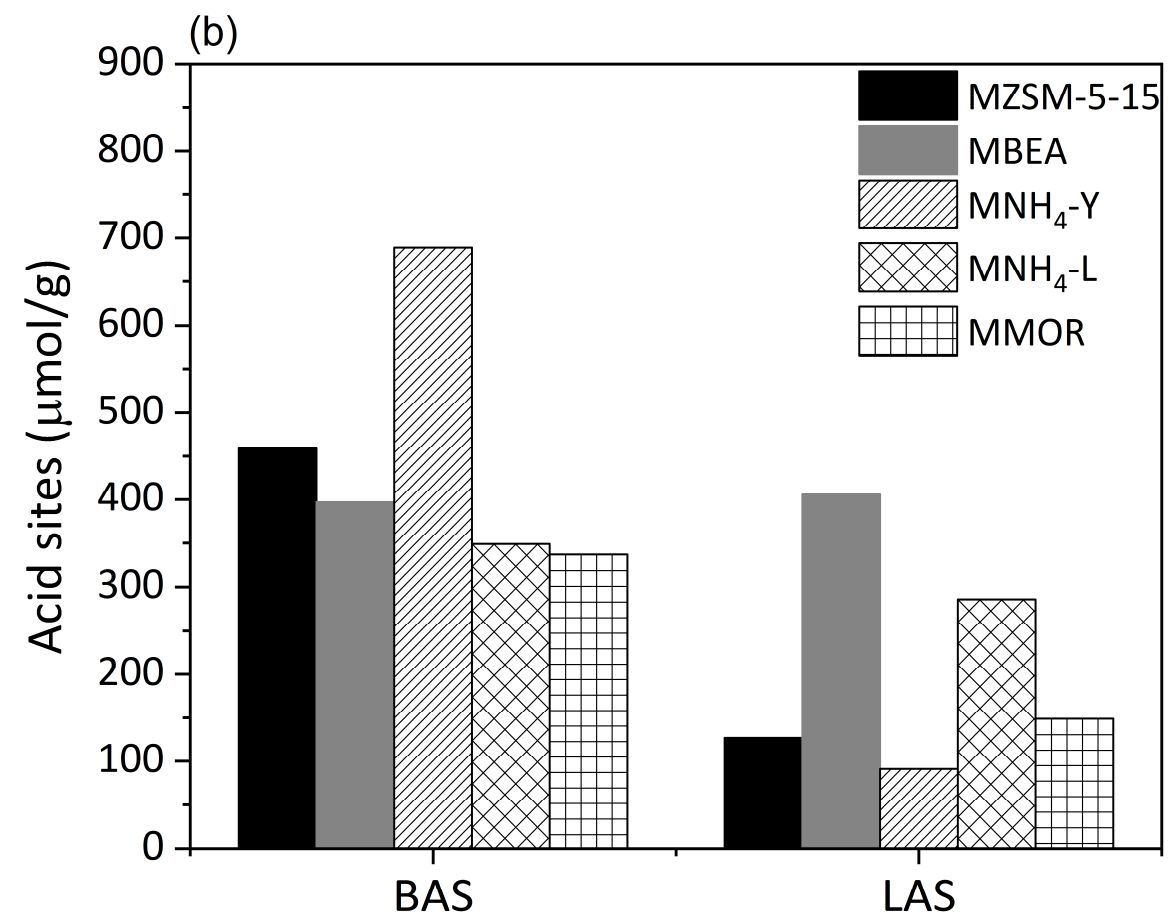

Figure 1. The concentration of acid sites in (a) parent and (b) hierarchical zeolites. 

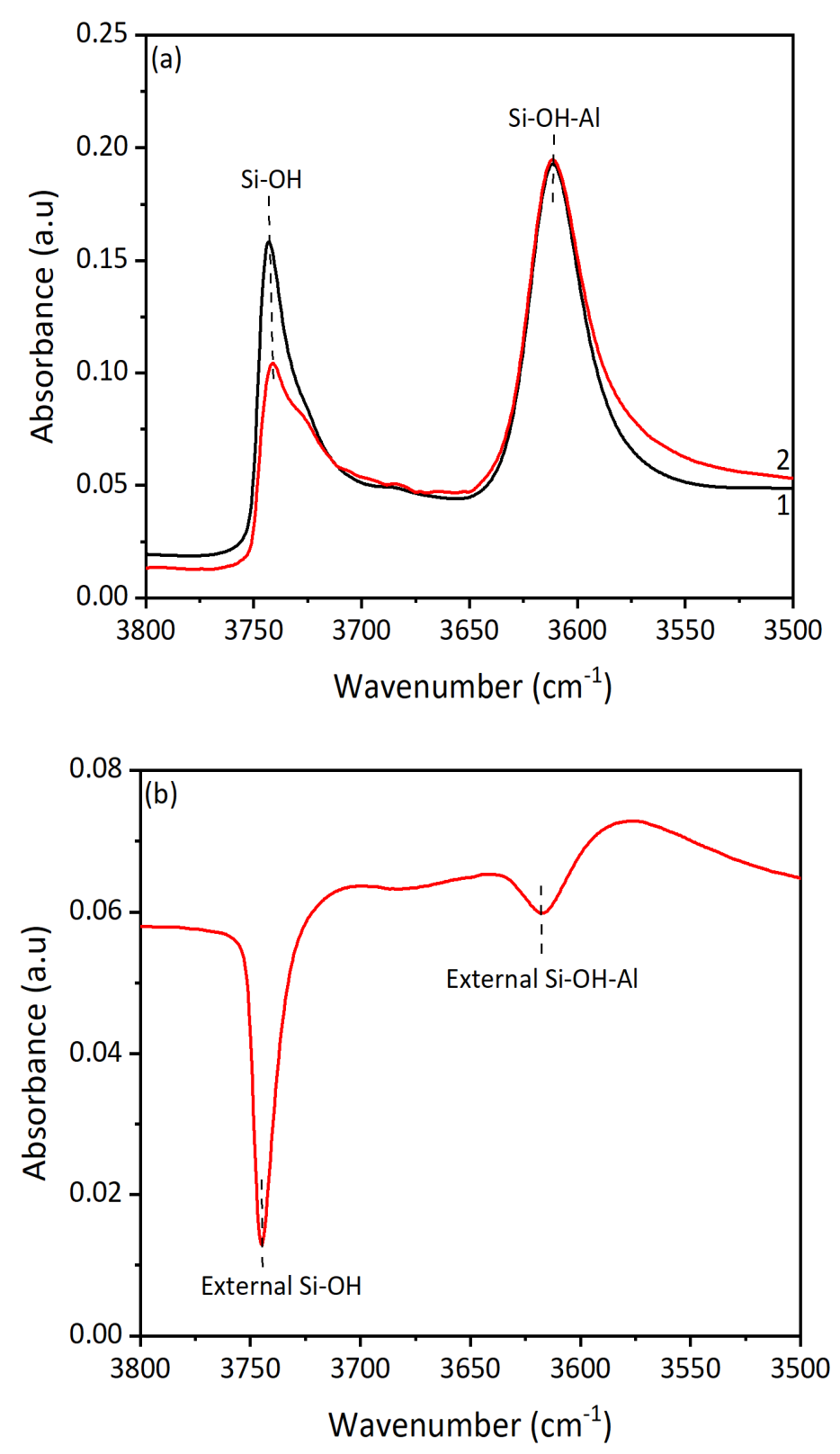

Figure 2. (a) FTIR spectra of the hydroxyl region of ZSM-5 zeolite (1) before and (2) after adsorption of TIPB at $30^{\circ} \mathrm{C}$. (b) Difference spectrum of ZSM-5 following adsorption of TIPB.

All BAS are accessible to Py in both $\mathrm{NH}_{4}-\mathrm{L}$ and $\mathrm{MNH}_{4}-\mathrm{L}$ samples, however, more BAS are accessible to Coll and TIPB in $\mathrm{NH}_{4}-\mathrm{L}$ (only semi-quantitative changes could be ascertained using

213 TIPB owing to the high concentration of Si-OH groups at $3745 \mathrm{~cm}^{-1}$ strongly interacting with this 214 probe molecule). Interestingly, our previous TEM studies have demonstrated a ñcore-shellò structure of the hierarchical $\mathrm{MNH}_{4}-\mathrm{L}$ [36]. Therefore, the lower overall accessibility of BAS in $\mathrm{MNH}_{4}-\mathrm{L}$ could be explained by the partial blocking of the ñcoreò regions by extraframework species generated during the acid or base treatment, while the ñshellò regions are characterised by the presence of regular mesopores with enhanced accessibility of the acid sites. 
There is no adequate probe molecule able to distinguish between BAS located on the external and internal surfaces of the faujasite structure. Owing to the large dimensions of the supercages (13 $\AA$ ), acid sites located in them are easily accessible to Coll and Py. Although the access to the supercages is restricted by the 12 -MR windows $(7.4 \AA \times 7.4 \AA)$, the experimental FTIR spectra demonstrate that even the bulky TIPB molecules interact with $~ 50 \%$ of BAS in large cages (Figure S6b), which is also in agreement with the reported TIPB reaction studies [36,44]. Therefore, the degree of interaction of Coll and Py with the BAS located in the smaller cages has been utilised as an indication of the acid site accessibility. Indeed, both Py and Coll adsorption monitored by FTIR has shown their improved access to the acid sites located in the small cages (low frequency bridging $\mathrm{OH}$ groups) of $\mathrm{NH}_{4}-\mathrm{Y}$ zeolites after the mesostructuring treatment (Table 1). This is probably due to the opening of sodalite cages following partial dissolution of the zeolite framework.

Table 1. Accessibility factors for hierarchical zeolites using different adsorbed probe molecules.

\begin{tabular}{|c|c|c|c|}
\hline Zeolite & $\operatorname{AF}_{P y}(\%)$ & $A F_{\text {Coll }}(\%)$ & $\mathrm{AF}_{\text {TIPB }}(\%)$ \\
\hline BEA & 100 & 100 & 10 \\
\hline MBEA & 100 & 100 & 22 \\
\hline $\mathrm{NH}_{4}-\mathrm{Y}^{*}$ & $100(\mathrm{HF}) 15(\mathrm{LF})$ & $100(\mathrm{HF}) 24(\mathrm{LF})$ & - \\
\hline $\mathrm{MNH}_{4}-\mathrm{Y}^{*}$ & $100(\mathrm{HF}) 46(\mathrm{LF})$ & $100(\mathrm{HF}) 49(\mathrm{LF})$ & - \\
\hline ZSM-5-15 & 100 & $4(4)^{* *}$ & - \\
\hline MZSM-5-15 & 100 & $4(6)^{* *}$ & - \\
\hline MOR & 73 & $22 * * *$ & 2 \\
\hline MMOR & 63 & $25^{* * *}$ & 12 \\
\hline $\mathrm{NH}_{4}-\mathrm{L}$ & 100 & 100 & 21 \\
\hline $\mathrm{MNH}_{4}-\mathrm{L}$ & 100 & 74 & $\sim 15$ \\
\hline
\end{tabular}

* HF and LF stand for high frequency and low frequency bridging $\mathrm{OH}$ groups in FAU. ** The data in brackets are calculated from the intensity of the Coll peak in the spectra. *** Depends on the time and temperature of the adsorption experiments.

Our FTIR results on the acidic properties of the parent and meso-microporous zeolites are in good agreement with the literature data demonstrating that the activity of these catalysts in dealkylation of TIPB increases following the mesostructuring treatment, which can be linked to the enhanced accessibility of the BAS $[36,44,45]$. In general, the obtained hierarchical zeolites show a greater degree of interaction with bulky probe molecules due to the shorter average length of the residual micropores between the newly formed mesopores, a significantly faster diffusion in the mesopores and a greater fraction of accessible acid sites. 


\subsection{Reaction Studies}

The esterification reaction has been carried out using a mixture of grapeseed oil with $\sim 12 \mathrm{v} \%$ of oleic acid as a model feedstock with a high FFA content. The conversion of oleic acid as a function of the reaction time over the parent and mesostructured zeolites at $100^{\circ} \mathrm{C}$ is presented in Figure 3 . The conversion increases steadily during the initial period of the reaction, reaching a plateau after 30-40 minutes. As can be seen from these data, the highest conversion is achieved on BEA and ZSM-5 zeolite catalysts. Although $\mathrm{NH}_{4}-\mathrm{Y}$ has a higher number of acid sites than other zeolites, the conversion of oleic acid over this material is not significantly different from that for MOR zeolite, whereas the $\mathrm{NH}_{4}-\mathrm{L}$ and $\mathrm{MNH}_{4}-\mathrm{L}$ zeolites show the lowest activity in this reaction.

(a)

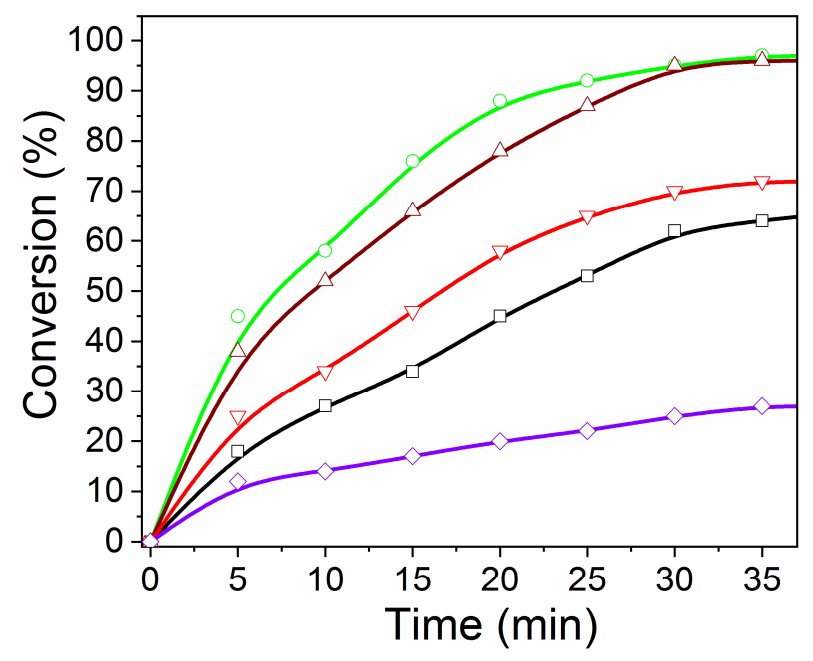

(b)

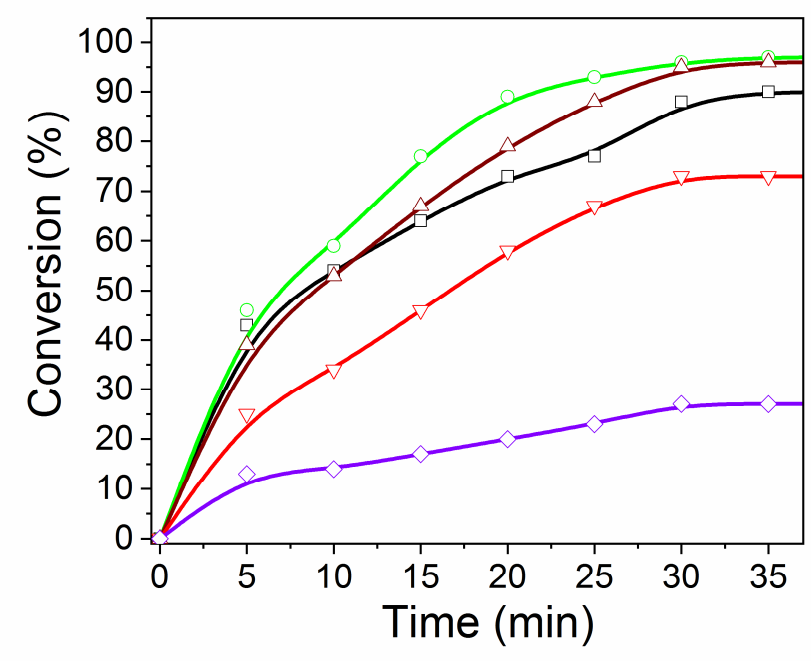

Figure 3. Conversion of oleic acid as a function of the reaction time for the parent (a) and hierarchical (b) zeolites: LTL (purple), Y (black), MOR (red), ZSM-5-15 (brown) and BEA (green). 
Interestingly, zeolite $\mathrm{Y}$ is the only catalyst whose activity has increased following the mesostructuring treatment, from the $65 \%$ conversion for $\mathrm{NH}_{4}-\mathrm{Y}$ to $90 \%$ for $\mathrm{MNH}_{4}-\mathrm{Y}$ after 35 min reaction time. These results indicate that the strength of acid sites available on the external surface of the zeolites, e.g. strong BAS in BEA and ZSM-5, determines their performance in the esterification reaction, while mild acid catalysts (FAU and LTL) require more ñuningò in order to achieve sustained high activity. Indeed, our FTIR data (Figures S7 and S8) show a greater shift in the frequency of the bridging $\mathrm{OH}$-groups interacting with hydrocarbons, such as n-nonane, for ZSM-5 and BEA zeolites, thus confirming their higher acid strength. The enhanced catalytic activity could be accomplished via partial dealumination and the introduction of a much more open pore system with the pore size greater than $5 \mathrm{~nm}$, as illustrated by the performance of the faujasite based catalysts. It should be noted that the selectivity towards FAME in the esterification reaction is close to $100 \%$ regardless of the conversion level. In addition, the conversion of oleic acid can be increased by changing the molar ratio between the feedstock oil and methanol. Our data confirm that the higher the molar ratio, the better mass transfer and miscibility are between the oil and methanol, which result in an increased conversion of oleic acid (Figure S9).

The results of the aldol condensation reaction carried out at $160^{\circ} \mathrm{C}$ are presented in Table 2 and Figures 4 and S10. The data obtained on the H-forms of the studied zeolites show the highest conversion for the large-pore zeolites with three-dimensional pore systems. Both the conversion of furfural and the yield of the target product, furfural acetone (FAc, 4-(2-furanyl)-3-bute-2-one), increase when the mesostructured zeolites with enhanced accessibility of acid sites are used as compared to their parent counterparts. It should be noted, that both $\mathrm{NH}_{4}-\mathrm{L}$ and $\mathrm{MNH}_{4}-\mathrm{L}$ zeolites show the lowest activity in aldol condensation, which could be attributed to the lower strength of the acid sites within the LTL structure. The selectivity towards FAc is similar for the acidic catalysts, between 80 and 95\%, with the main by-product being 4-methyl-3-penten-2one (4-MP), which is formed as the result of acetone self-condensation catalysed by the zeolite acid sites. Hence, it may be difficult to control the product selectivity over these solid acids, as the BAS can catalyse a range of side reactions, such as acetone condensation, dehydration, etc. Since aldol condensation can be catalysed by both acids and basis, some reaction studies have been conducted on the Kexchanged LTL and FAU zeolites. From the composition of these zeolites having a relatively low $\mathrm{Si} / \mathrm{Al}$ ratio, they should have a greater negative charge on the framework oxygen atoms, and therefore, more pronounced basic properties. Interestingly, the main reaction product obtained is the targeted FAc without any noticeable acetone self-condensation. The selectivity to FAc (the desired product) is largely determined by the type of active sites, basic or acidic, as the same ( 100\%) selectivity to FAc over the K-forms of Y and LTL zeolites has been observed at much shorter reaction times and lower furfural conversion. In addition, both potassium-exchanged 

potential advantage of utilising basic meso-microporous zeolites in this reaction.

292
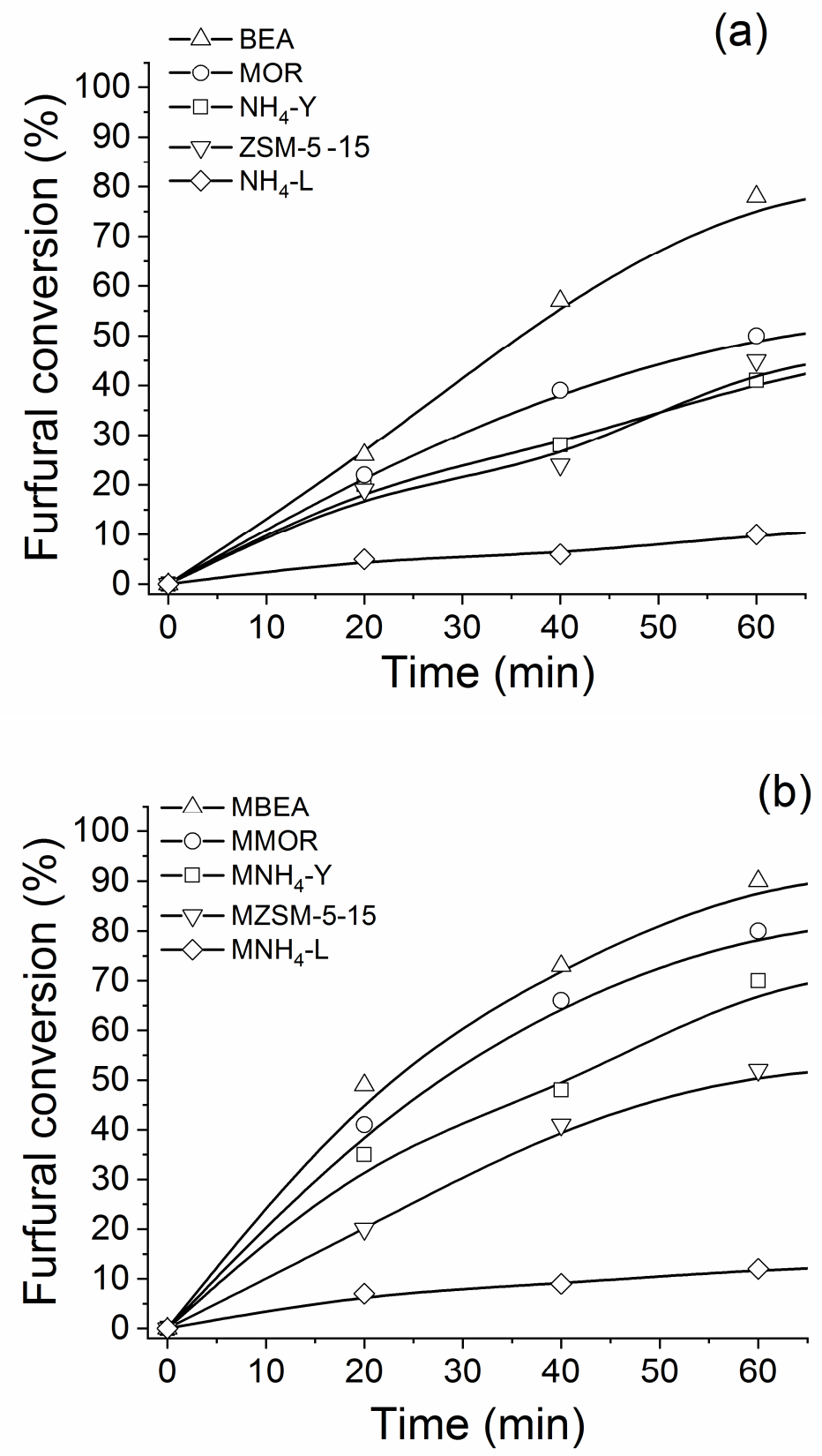

Figure 4. Furfural conversion over parent (a) and (b) hierarchical zeolites. 
Table 2. Catalytic performance of Y and LTL zeolites in aldol condensation between furfural and acetone.

\begin{tabular}{|c|c|c|c|c|c|}
\hline \multirow[t]{2}{*}{ Catalyst } & \multirow{2}{*}{$\begin{array}{c}\text { Reaction } \\
\text { Time } \\
\text { (min) }\end{array}$} & \multirow{2}{*}{$\begin{array}{c}\text { Conversion } \\
\text { of Furfural } \\
(\%) \\
\end{array}$} & \multicolumn{2}{|c|}{$\begin{array}{c}\text { Selectivity } \\
\text { (mol \%) }\end{array}$} & \multirow{2}{*}{$\begin{array}{c}\text { Yield } \\
\text { of FAc } \\
(\%) \\
\end{array}$} \\
\hline & & & FAc & 4-MP & \\
\hline $\mathrm{NH}_{4}-\mathrm{Y}$ & 60 & 41 & 95 & 5 & 39 \\
\hline $\mathrm{MNH}_{4}-\mathrm{Y}$ & 60 & 70 & 95 & 5 & 67 \\
\hline $\mathrm{K}-\mathrm{Y}$ & 60 & $>60$ & $>99$ & - & $>60$ \\
\hline MK-Y & 60 & $>95$ & $>99$ & - & $>95$ \\
\hline $\mathrm{NH}_{4}-\mathrm{L}$ & 60 & 10 & 95 & 5 & 10 \\
\hline $\mathrm{MNH}_{4}-\mathrm{L}$ & 60 & 12 & 95 & 5 & 12 \\
\hline NaK-L & 60 & 95 & $>99$ & - & 95 \\
\hline MK-L & 60 & $>95$ & $>99$ & - & $>95$ \\
\hline
\end{tabular}

297

298

299

300

301

302

303

304

305

306

307

308

309

310

311

312

313

314

315

316

317

The catalytic activity and selectivity of the regenerated zeolites (following calcination at $450^{\circ} \mathrm{C}$ ) has not changed significantly after four consecutive runs performed under the same reaction conditions. The recycled hierarchical zeolites catalysts showed a very similar oleic acid conversion and FAc yield compared with the fresh zeolites (Figure S11). The structural characterisation of the used catalysts, which have been subjected to the activation-reaction-regeneration cycles, has shown no change in the crystallinity of the K- and Na-forms of Y and LTL and in the H-forms of highsilica zeolites, such as BEA, whereas the crystallinity of H-form of Y zeolite does decrease by $\sim 30 \%$ (Figure S12). At the same time, there is a noticeable reduction $(\sim 20 \%)$ in the number of the BAS and a similar increase in the number of LAS in the regenerated BEA (Figure S13). FTIR spectra of the activated and regenerated $\mathrm{NH}_{4}-\mathrm{Y}$ show a significant reduction in the number of BAS. For the latter catalyst, both XRD and infrared data confirm a considerable degree of dealumination and the formation of LAS associated with extra-framework aluminium species. These results indicate that although the presence of mesopores can enhance the catalyst resistance to deactivation, due to a faster diffusion of the coke precursors out of the mesopores, the long-term structural stability of some zeolites, particularly H-forms with a high Al content ( $\mathrm{Y}$ and LTL), during multiple reaction-regeneration cycles would require further improvement.

\section{Conclusions}

In summary, hierarchical zeolites have been prepared in this work using the surfactanttemplated mesostructuring strategy and utilised as potential catalysts in the esterification reaction of 
free fatty acid and in the aldol condensation reaction between furfural and acetone. Overall, the structural characterisation of the meso-microporous zeolites coupled with FTIR studies demonstrate a successful generation of the intracrystalline mesoporosity in large-pore zeolites with enhanced accessibility of the acid sites in hierarchical zeolites. Although the treatment has not altered the catalytic efficiency of BEA, ZSM-5, MOR and L to remove the oleic acid from grape seed oil, which appears to be determined by the strength of BAS, a higher conversion of oleic acid can be achieved over the hierarchal faujasites due to the combination of improved accessibility of stronger acid sites and lower mass transport limitations. The results obtained for aldol condensation confirm that the zeolite structure and acidic or basic properties are essential factors for directing this reaction to the desired products. The interaction between the furfural and acetone over acidic hierarchical zeolites results in a high furfural conversion, however, a parallel reaction of acetone selfcondensation leads to a lower yield of FAc. The introduction of basic sites significantly improves the selectivity towards the target aldol condensation product. Overall, mesostructured zeolites demonstrate an improved catalytic performance as a result of increasing accessibility of their active sites. However, the right balance between the acidic and basic properties of these catalysts is essential for achieving optimum activity and selectivity.

\section{Acknowledgments}

The authors thank the Ministry of Oil, Oil Marketing Company (SOMO, Baghdad, Iraq) for the funding provided under the grant SL-144-04B. We gratefully acknowledge Johnson Matthey PLC and Keele University for their support and funding provided for this work as the studentship for C.F. The authors would like to thank Prof. J. Garcia-Martinez and Dr. E. Li for useful advice regarding the synthesis of surfactant-templated FAU and MOR zeolites.

\section{Supplementary Information}

Supplementary data for this article can be found on-line at:

\section{Conflict of interest.}

The authors declare no competing financial interest.

\section{References}

1 Perego, C.; Bosetti, A.; Ricci, M.; Millini, R. Zeolite Materials for Biomass Conversion to Biofuel. Energy Fuels, 2017, 31, 7721-7733. 
2 Armaroli, N.; Balzani, V. The Future of Energy Supply: Challenges and Opportunities. Angew. Chem. Int. Ed., 2007, 46, 52-66.

3 Igathinathane, C.; Sanderson, M. Biofuel Feedstock: Challenges and Opportunities. Green Chemistry for Sustainable Biofuel Production: Apple Academic Press; 2018. p. 37-78.

4 Lange, J.; Van Der Heide, E.; van Buijtenen, J.; Price, R. Furfural-A Promising Platform for Lignocellulosic Biofuels. ChemSusChem, 2012, 5, 150-166.

5 Climent, M.J.; Corma, A.; Iborra, S. Conversion of biomass platform molecules into fuel additives and liquid hydrocarbon fuels. Green Chem, 2014, 16, 516-547.

6 Nakagawa, Y.; Tamura, M.; Tomishige, K. Catalytic reduction of biomass-derived furanic compounds with hydrogen. ACS Catalysis, 2013, 3, 2655-2668.

7 Smoláková, L.; Frolich, K.; Kocík, J.; Kikhtyanin, O.; Lapek, L. Surface properties of hydrotalcite-based $\mathrm{Zn}(\mathrm{Mg}) \mathrm{Al}$ oxides and their catalytic activity in aldol condensation of furfural with acetone. Ind Eng Chem Res, 2017, 56, 4638-4648.

8 Chung, K.; Chang, D.; Park, B. Removal of free fatty acid in waste frying oil by esterification with methanol on zeolite catalysts. Bioresource Technol, 2008, 99, 7438-7443.

9 López, D.E.; Goodwin, J.G. Jr.; Bruce, D.A; Furuta, S. Esterification and transesterification using modified-zirconia catalysts. Applied Catalysis A: General, 2008, 339, 76-83.

10 Pirez, C.; Lee, A.F.; Manayil, J.C.; Parlett, C.M.A.; Wilson, K. Hydrothermal saline promoted grafting: a route to sulfonic acid SBA-15 silica with ultra-high acid site loading for biodiesel synthesis. Green Chem, 2014, 16, 4506-4509.

11 Mbaraka, I.K.; Radu, D.R.; Lin, V.S.Y.; Shanks, B.H. Organosulfonic acid-functionalized mesoporous silicas for the esterification of fatty acid. J Catal, 2003, 219, 329-336.

12 Kikhtyanin, O.; Ganjkhanlou, Y.; Kubiḷka, D.; Bulánek, R.; Lejka, J. Characterization of potassium-modified FAU zeolites and their performance in aldol condensation of furfural and acetone. Applied Catalysis A: General, 2018, 549, 8-18.

13 Bohre, A.; Saha, B.; Abu-Omar, M.M. Catalytic Upgrading of 5-Hydroxymethylfurfural to Drop-in Biofuels by Solid Base and Bifunctional Metal-Acid Catalysts. ChemSusChem, 2015, 8, 4022-4029.

14 Philippou, A.; Anderson, M.W. Aldol-Type Reactions over Basic Microporous Titanosilicate ETS-10 Type Catalysts. J. Catal., 2000, 189, 395-400.

15 Ramos, R.; Hidalgo, J.M.; Göpel, M.; Tig̉er, Z.; Bertella, F.; Martínez, A.; Kikhtyanin, O.; Kubil ka, D. Catalytic conversion of furfural-acetone condensation products into bio-derived C8 linear alcohols over NiCu/Al-SBA-15. Catalysis Comm., 2018, 114, 42-45. 
16 Verboekend, D.; Pérez-Ramírez, J. Design of hierarchical zeolite catalysts by desilication. Catalysis Science \& Technology, 2011, 1, 879-890.

17 Aguado, J.; Sotelo, J.; Serrano, D.; Calles, J.; Escola, J. Catalytic conversion of polyolefins into liquid fuels over MCM-41: पcomparison with ZSM-5 and amorphous $\mathrm{SiO}_{2} \overline{\mathrm{I}} \mathrm{Al}_{2} \mathrm{O}_{3}$. Energy Fuels, 1997, 11, 1225-1231.

18 V.L. Zholobenko, A.Y. Khodakov, D. Durand, Synchrotron x-ray diffraction-diffusion studies of the preparation of SBA-15 materials. Microporous Mesoporous Mater., 2003, 66, 297-302.

19 Perez-Ramirez, J.; Christensen, C.H.; Egeblad, K.; Christensen, C.H.; Groen, J.C. Hierarchical zeolites: enhanced utilisation of microporous crystals in catalysis by advances in materials design. Chem. Soc. Rev., 2008, 37, 2530-2542.

20 Huang, S.; Liu, X.; Yu, L.; Miao, S.; Liu, Z.; Zhang, S.; Xie, S.; Xu, L. Preparation of hierarchical mordenite zeolites by sequential steaming-acid leaching-alkaline treatment. Microporous Mesoporous Mater, 2014, 191,18-26.

21 Serrano, D.P.; Sanz, R.; Pizarro, P.; Moreno, I.; Shami, S. Narrowing the mesopore size distribution in hierarchical TS-1 zeolite by the surfactant-assisted reorganization. Microporous Mesoporous Mater, 2014, 189, 71-82.

22 Jiang, J.; Yu, J.; Corma, A. Extra Large Pore Zeolites: Bridging the Gap between Micro and Mesoporous Structures. Angew Chem Int Ed, 2010, 49, 3120-3145.

23 M. Impéror-Clerc, I. Grillo, A.Y. Khodakov, D. Durand, V.L. Zholobenko, New insights into the initial steps of the formation of SBA-15 materials: an in situ small angle neutron scattering investigation. ChemComm., 2007, 8, 834-836.

24 Opanasenko, M.V.; Roth, W.J.; Cejka, J. Two-dimensional zeolites in catalysis: current status and perspectives. Catalysis Science \& Technology, 2016, 6, 2467-2484.

25 Mitchell, S.; Pinar, A.B.; Kenvin, J.; Crivelli, P.; Kärger, J.; Pérez-Ramírez, J. Structural analysis of hierarchically organized zeolites. Nat Commun, 2015, 6, 8633.

26 Khan, W.; Jia, X.; Wu, Z.; Choi, J.; Yip, A.C.K. Incorporating hierarchy into conventional zeolites for catalytic biomass conversions: a review. Catalysts. 2019, 9, 127.

27 Milina, M.; Mitchell, S.; Pérez-Ramírez, J. Prospectives for bio-oil upgrading via esterification over zeolite catalysts. Catal Today, 2014, 235, 176-183.

28 J. Datka, K. Tarach, K. Góra-Marek, Acidic properties of hierarchical zeolites in nesoporous zeolites: preparation, characterization, and applications. In: Mesoporous zeolites: preparation, characterization, and applications. John Wiley \& Sons., 2015, 461-496.

29 Y. Wei, T. E. Parmentier, K. P. de Jong and J. Zel evil . Tailoring and visualizing the pore architecture of hierarchical zeolites. Chem. Soc. Rev., 2015, 44, (20), 7234-7261. 
30 M. Milina, S. Mitchell, P. Crivelli, D. Cooke and J. Pérez-Ramírez. Mesopore quality determines the lifetime of hierarchically structured zeolite catalysts. Nat. Commun., 2014, 5, 3922-3932.

$31 \mathrm{~K}$. Hadjiivanov. Identification and characterization of surface hydroxyl groups by infrared spectroscopy. Adv. Catal., 2014, 57, 99-318.

32 D. Zhai, Y. Li, H. Zheng, L. Zhao, J. Gao, C. Xu, B. Shen. A first-principles evaluation of the stability, accessibility, and strength of Brønsted acid sites in zeolites. J. Catal., 2017, 352, 627-637.

33 F. L. Bleken, K. Barbera, F. Bonino, U. Olsbye, K. P. Lillerud, S. Bordiga, P. Beato, T. V. W. Janssens, S. Svelle. Catalyst deactivation by coke formation in microporous and desilicated zeolite H-ZSM-5 during the conversion of methanol to hydrocarbons. J. Catal., 2013, 307, 62-73.

34 F. Thibault-Starzyk, I. Stan, S. Abelló, A. Bonilla, K. Thomas, C. Fernandez, J.-P. Gilson and J. Pérez-Ramírez. Quantification of enhanced acid site accessibility in hierarchical zeolites $\ddot{I}$ the accessibility index. J. Catal., 2009, 264, (1), 11-14.

35 S. Bordiga, C. Lamberti, F. Bonino, A. Travert and F. Thibault-Starzyk. Probing zeolites by vibrational spectroscopies. Chem. Soc. Rev., 2015, 44, (20), 7262-7341.

36 Al-Ani, A.; Haslam. J.C.J.; Mordvinov. N. E. ; Lebedev O. I.; A. Vicente, Fernandez C., Zholobenko. V. Synthesis of Nanostructured Catalysts by Surfactant-Templating of Large-Pore Zeolites. Nanoscale Advances, 2019, 1, 2029-2039.

37 Ying, J.Y.; Garcia-Martinez, J. Mesostructured zeolitic materials, and methods of making and using the same.US patent, No.7,589,041B2, 2009.

38 Pérez-Ramírez, J.; Verboekend, D.; Bonilla, A.; Abelló, S. Zeolite Catalysts with Tunable Hierarchy Factor by Pore-Growth Moderators. Adv Func Mater, 2009, 19, 3972-3979.

39 N. S. Nesterenko, F. Thibault-Starzyk, V. Montouillout, V. V. Yuschenko, C. Fernandez, J.-P. Gilson, F. Fajula, I.I. Ivanova. The use of the consecutive adsorption of pyridine bases and carbon monoxide in the IR spectroscopic study of the accessibility of acid sites in microporous/mesoporous materials. Kinet. Katal., 2006, 47 (1), 40-48.

40 Ođ̃Keefe, S.F.; Pike, O.A. Fat characterization. Food analysis: Springer; 2010. p. 239-260.

41 Kikhtyanin, O.; Kelbichová, V.; Vitvarová, D.; KubT, M.; Kubil ka, D. Aldol condensation of furfural and acetone on zeolites. Catalysis Today, 2014, 227,154-162.

42 Busca. G. Acidity and basicity of zeolites: A fundamental approach. Microporous Mesoporous Mater., 2017, 254, 3-16.

43 Thibault-Starzyk, F.; Stan I.; Abelló, S.; Bonilla A.; Thomas K.; Fernandez, C.; Gilson J-P.; J. Pérez-Ramírez. Quantification of enhanced acid site accessibility in hierarchical zeolites $\ddot{i}$ The accessibility index. J. Catal., 2009, 264, 11-14. 
44 Qin, Z.; Cychosz, K.A.; Melinte, G.; El Siblani, H.; Gilson, J-P.; Thommes, M.; Fernandez, C.; Mintova, S.; Ersen, O.; Valtchev, V. Opening the Cages of Faujasite-Type Zeolite. J. Am. Chem. Soc., 2017, 139, 17273-17276.

45 Lei Q., Zhao T., Li F., Zhang L., Wang Y., Catalytic cracking of large molecules over hierarchical zeolites, ChemComm, 2006, 1769-1771. 